\title{
Taman Bermain Dengan Pendekatan Arsitektur Hijau Di SUKOHARJO
}

Tri Hesti Shinta Dewi, Maya Andria Nirawati, Kusumaningdyah NH

Program Studi Arsitektur

Jurusan Arsitektur Fakultas Teknik

Universitas Sebelas Maret Surakarta

Email : shinshinta_dewi@yahoo.co.id

\begin{abstract}
The background of Playground design in Sukoharjo is the lack of container for recreational play area and the lack of green spaces in Sukoharjo. As an example of the present is the of variety games for children in Sukoharjo square, which makethe location become dense and crowded so it can cause the possibility of an accident. The Games also don't have education value in it, whereas public space as a place of recreation that educate is necessary to increase the interest in learning, especially for children. Listed on thr Spatial Plan Sukoharjo period 2010-2030, Sukoharjo have a plan that there is a place for recreation development. Problem design is how for designing educative and recreative playground place or recreation that fit for all ages. The method is based on the concept of Green Architecture with the cozy atmosphere is created by the climate-responsive design and environmentally friendly. The obtained result is a playground that makes the architectural elements of design principles are explored, that building is climate-responsivie design and enviromentally friendly. Green archintecture is also applied as a means of education and recreation,the use of recycled goods for furnituture site and building materialswhich also privide insight and education for society that the goods are considered to be unusable apparently still can be used again.
\end{abstract}

Keywords: Educative, Green Architecture, Playground, Public Space, Recreation

\section{PENDAHULUAN}

Perancangan Taman Bermain di Sukoharjo dilatarbelakangi oleh tidak adanya wadah untuk area rekreasi bermain dan minimnya ruang hijau kota di Sukoharjo. Seperti contoh yang ada sekarang yaitu munculnya berbagai wahana permainan untuk anak-anak yang terdapat di Alun-Alun Sukoharjo, yang menjadikan lokasi tersebut padat dan macet sehingga tidak menutup kemungkinan terjadi kecelakaan. Permainan yang ada hanya untuk anak-anak saja, sedangkan pengunjung dewasa lebih banyak namun tidak ada wadah atau kegiatan yang bisa mereka lakukan selain hanya melihat suasana keramaian di sana. Permainan yang ada pun tidak memiliki unsur edukasi didalamnya, padahal ruang publik sebagai tempat rekreasi yang mendidik sangatlah perlu untuk meningkatkan minat belajar khususnya untuk anak-anak. Melihat potensi yang ada di Sukoharjo yaitu terdapat rencana pengembangan tempat rekreasi yang tercantum pada Rencana Tata Ruang Wilayah Kota Sukoharjo, maka dengan mendesain sebuah tempat/area rekreasi yang diperuntukkan untuk semua kalangan usia merupakan hal yang cocok untuk memberi solusi pada fenomena tersebut.

Pada tempat rekreasi kenyamanan merupakan hal yang harus diperhatikan. Suasana nyaman diciptakan dengan desain yang responsif terhadap iklim dan ramah lingkungan. Pada rencana desain tersebut, Arsitektur Hijau menjadi solusi desain yang tepat bagi obyek yang direncakanan. Hasil yang diperoleh merupakan sebuah taman bermain yang menjadikan elemen arsitektural sebagai prinsip desain yang dieksplor serta menjadi sarana edukasi dan rekreasi. Pada perancangan di sini terdapat tiga hal yang difokuskan untuk desain nantinya yaitu bangunan, lanskap, dan sirkulasi.

\section{METODE}

Untuk mendapatkan desain akhir yang diinginkan yaitu sebuah taman bermain yang responsif terhadap iklim dan ramah lingkungan serta sebagai sarana edukasi dan rekreasi, metode yang digunakan mengacu pada konsep 
Arsitektur Hijau. Pada perencanaan taman bermain, Arsitektur Hijau diaplikasikan pada tiga point, di antaranya:

1. Bangunan

Arsitektur Hijau yang diterapkan pada bangunan adalah konsep bangunan yang responsif terhadap iklim yang sesuai dengan karakteristik Arsitektur Hijau dari bentuk massa, bentuk atap, material dan struktur.

2. Lanskap

Arsitektur Hijau yang diterapkan pada lanskap adalah konsep taman hemat energi dan penggunaan recycle sclupture yang menjadi furnirur tapak nantinya.

3. Sirkulasi

Arsitektur Hijau yang diterapkan pada sirkulasi adalah melalui kemudahan dan kenyamanan. Sirkulasi yang terdapat di luar bangunan berupa skywalk dengan tujuan konservasi tanah yang berkontur pada tapak. Skywalk menggunakan material lokal dan daur ulang sesuai dengan karakteristik Arsitektur Hijau.

\section{ANALISIS}

\subsection{Analisis Peruangan}

Analisis peruangan bertujuan untuk merencanakan ruang-ruang yang dibutuhkan bagi pengguna taman bermain (lihat tabel 1).

Tabel 1.Kebutuhan Ruang

\begin{tabular}{|l|l|l|}
\hline \multirow{2}{*}{ PELAKU } & \multicolumn{1}{|c|}{ KEGIATAN } & \multicolumn{1}{c|}{ RUANG } \\
\hline \multirow{4}{*}{$\begin{array}{l}\text { Pengunjun } \\
\text { g }\end{array}$} & Datang & Hall penerima \\
\cline { 2 - 3 } & Membeli karcis & R. Loket \\
\cline { 2 - 3 } & $\begin{array}{l}\text { Bermain dan } \\
\text { belajar }\end{array}$ & Wahana indoor \\
\cline { 2 - 3 } & $\begin{array}{l}\text { Eksplorasi alam } \\
\text { dan rekreasi }\end{array}$ & Wahana outdoor \\
\cline { 2 - 3 } & Ibadah & Mushola \\
\cline { 2 - 3 } & Metabolisme & Lavatory \\
\hline \multirow{2}{*}{ Pengelola } & Datang & Hall penerima \\
\cline { 2 - 3 } & Absensi & Ruang absen \\
\hline & $\begin{array}{l}\text { Mengurus } \\
\text { Pengelolaan }\end{array}$ & $\begin{array}{l}\text { Ruang } \\
\text { pengelola }\end{array}$ \\
\hline & $\begin{array}{l}\text { Memandu } \\
\text { kegiatan wahana }\end{array}$ & Ruang pemandu \\
\hline & Ibadah & Mushola \\
\hline & Metabolisme & Lavatory \\
\hline
\end{tabular}

\subsection{Analisis Lokasi}

Selain menentukan lokasi yang strategis, memilih tapak dengan kondisi yang mendukung keberadaan taman bermain ini sangat menentukan prospek objek tersebut.

1. Tujuan

Mendapatkan lokasi tapak yang mendukung untuk taman bermain dan sesuai dengan RTRW Kota Sukoharjo.

2. Dasar pertimbangan

Posisi tapak strategis untuk mengekspos tampilan fisik objek, luasan tapak dapat menampung seluruh kebutuhan ruang yang direncanakan.

\subsection{Analisis Pencapaian}

Pencapaian ke dalam bangunan harus mudah diakses, mudah dilihat dan memiliki sirkulasi yang aman akan menstimulus orang untuk masuk dalam area bangunan.

1. Tujuan: menentukan main entrane, menentukan side entrance

2. Dasar Pertimbangan: kemudahan akses, sirkulasi tapak yang aksesibel, arus kendaraan dan potensi jalan, tingkat keamanan.

3. Proses analisis

Main Entrance (ME)

Mudah dijangkau dan terlihat dengan jelas. Menghadap langsung ke arah jalan utama untuk kemudahan sirkulasi kendaraan masuk dan ke luar tapak.

Side Entrance (SE)

Diperuntukan untuk semua staff pengelola dan loading dock sehingga peletakkannya tidak berhubungan langsung dengan ME dengan harapan masuknya kendaraan ke SE tidak mengganggu akses ME.

Berikut adalah gambar yang menjelaskan peletakkan ME dan SE (lihat gambar 1).

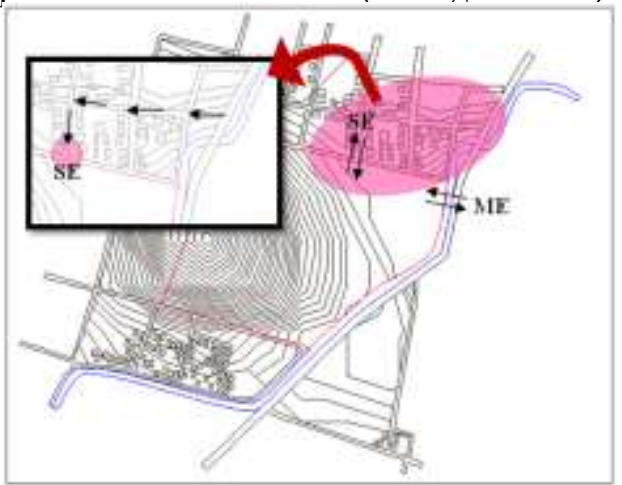

Gambar 1. Pola Pencapaian 


\subsection{Analisis Pemintakatan (Penzoningan)}

Pemintakatan berdasarkan sifat kegiatan dan keadaan dalam tapak dilakukan sebagai acuan dalam penataan peruangan, namun tetap memperhatikan modul-modul struktur yang telah diterapkan.

1. Tujuan: Menentukan mintakat (zoning) berdasarkan sifat kegiatan dan keadaan pada tapak.

2. Dasar pertimbangan: analisis peruangan, analisis pengolahan tapak, analisis struktur.

3. Proses analisis: persyaratan ruang, berdasarkan kelompok kegiatan dan analisis pengolahan tapak.

Berikut adalah gambar yang menjelaskan pembagian zona pada tapak (lihat gambar 2).

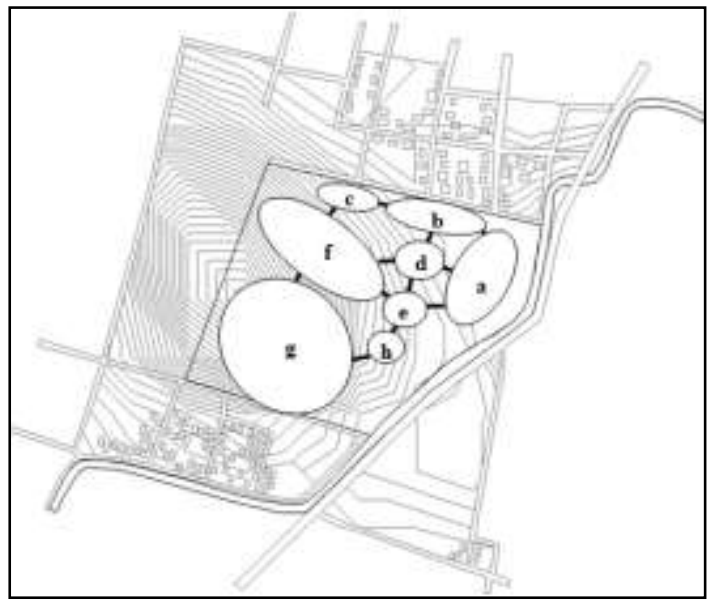

Gambar 2. Pola Permintakan

Keterangan:

a. Zona ruang hijau dan playground

b. Zona parkir

c. Zona energi dan utilitas

d. Zona pengelola

e. Zona penerima

f. Zona bermain dan belajar

g. Zona eksplorasi alam dan rekreasi

h. Zona penunjang

\subsection{Analisis Bentuk dan Tampilan Kawasan 3.5.1 Analisis Bentuk Bangunan}

Bentuk bangunan yang hemat energi adalah bangunan yang memanjang dan tipis (Brenda dan Vale, 1996), dan bentuk atap yang responsif terhadap iklim yaitu menggunakan bentuk atap miring (Karyono, 2010). Material penggunaan atap menggunakan genteng tanah liat karena merupakan produksi lokal di Sukoharjo.
Berikut adalah gambar-gambar yang menjelaskan bentuk dasar massa dan bentuk atap tiap bangunan (lihat gambar $3)$.

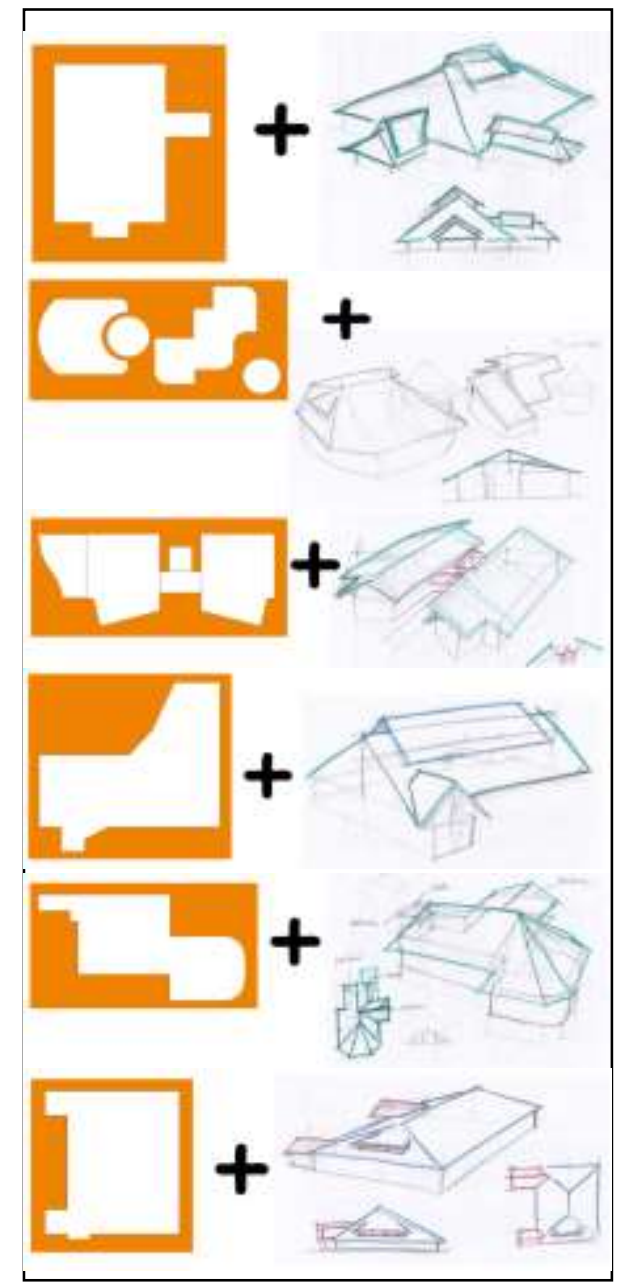

Gambar 3. Bentuk Dasar Massa dan Bentuk Atap Tiap Bangunan

\subsubsection{Penampilan Lanskap}

1.Taman Hemat Energi, meliputi: pemilihan jenis tanaman yang sesuai, pemilihan vegetasi berdasarkan fungsi, model artificial, penyediaan elemen air, pencahayaan yang hemat energi, penggunaan material lokal, rancang di tempat, dan pengerjaan manual (Christina, 2013).

2. Recycle Sclupture, yaitu menggunakan barang-barang daur ulang untuk furnitur tapak, seperti gambar berikut (lihat gambar 4). 


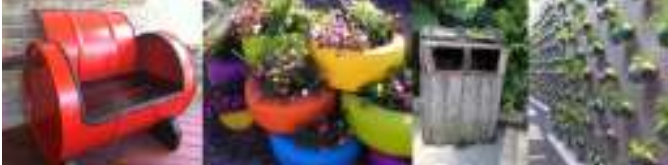

Gambar 4. Barang-barang Daur Ulang Sumber: http://www.google.com

\subsubsection{Penampilan Sirkulasi Kawasan}

Sirkulasi kawasan yang dipergunakan adalah jenis sirkulasi tunggal. Sirkulasi tunggal bersifat fleksibel yang bisa menjangkau ke semua wahana. Kondisi tanah tapak yang berkontur dan adanya konservasi tanah pada konsep Arsitektur Hijau dengan meminimalisir cut and fill, maka media sirkulasi memakai skywalk dengan alasan agar tanah dibiarkan apa adanya. Skywalk menggunakan material lokal dan daur ulang.

Berikut adalah gambar yang menjelaskan bentuk skywalk dan material yang digunakan (lihat gambar $5)$.

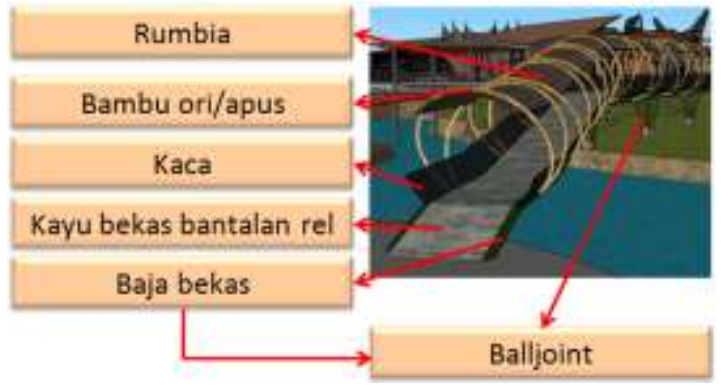

Gambar 5. Skywalk

\section{KESIMPULAN (KONSEP DESAIN)}

Dari hasil analisis serta hasil korelasi dari beberapa data di atas, maka diperoleh hasil berupa desain Taman Bermain di Sukoharjo sebagai berikut.
Lokasi
: Jalan utama
Tawangsari
Luas Lahan
: $79.723 \mathrm{~m}^{2}$
Daya Tampung
: 10.000 orang

Berikut adalah gambar perspektif kawasan tapak (lihat gambar 6).

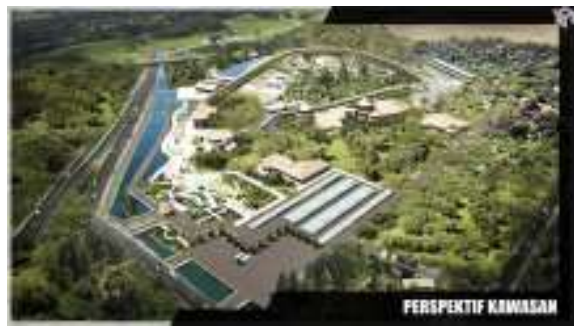

Gambar 6. Perspektif Kawasan

Penerapan Arsitektur Hijau pada taman bermain terletak pada beberapa hal:

1.Konservasi tanah pada tapak yang berkontur dengan mengupayakan meminimalisir cut and fill dengan penerapan sistem panggung (lihat gambar 7).

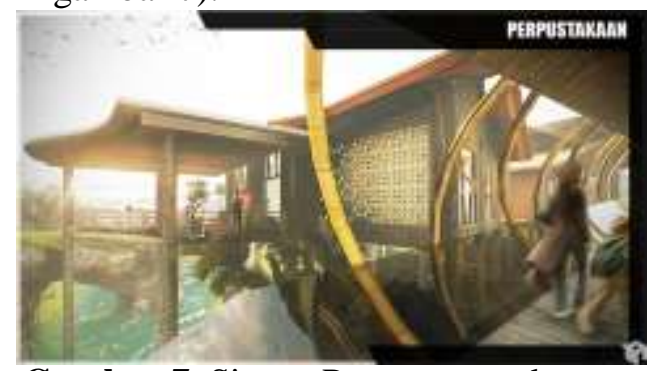

Gambar 7. Sistem Panggung pada Bangunan

2. Bangunan yang responsif terhadap iklim meliputi bentuk dasar massa yang tipis memanjang, penggunaan atap miring, penggunaan struktur sistem panggung, dan penggunaan material lokal untuk selimut bangunan (lihat gambar 8).

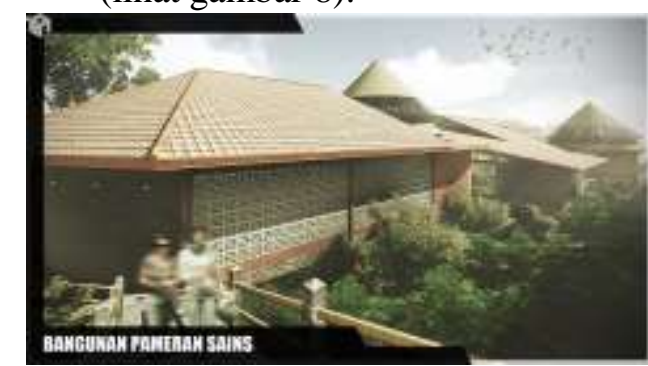

Gambar 8. Bangunan Tipis Memanjang Beratap Miring dengan Material Lokal.

3. Membuat taman yang hemat energi meliputi penggunaan material, pengerjaan, dan dalam pengoperasian atau perawatannya.

4. Penggunan bahan-bahan daur ulang dan material lokal yang diaplikasikan pada elemen-elemen keras taman dan bangunan (lihat gambar 9). 


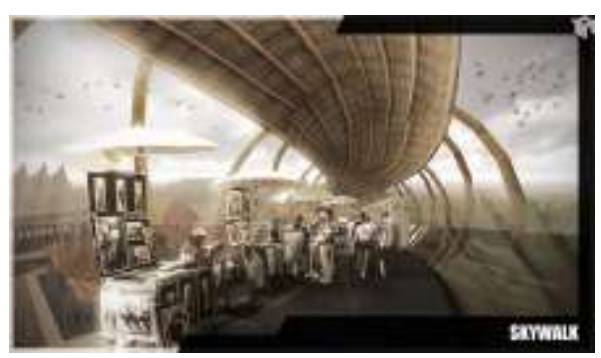

Gambar 9. Penggunaan Material dari Barang Daur Ulang dan Bahan Lokal.

5. Sirkulasi yang fleksibel bisa menjangkau ke semua wahana sehingga efisien (lihat gambar 10).

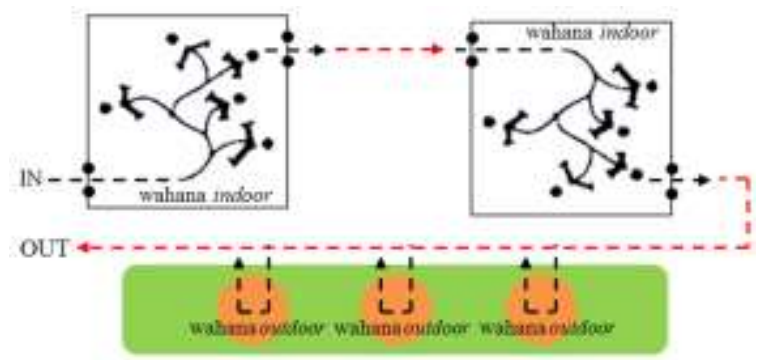

Gambar 10. Sirkulasi yang Efisien

6. Penggunaan panel surya yang diletakkan pada area parkir sekaligus sebagai atap untuk area parkir (lihat gambar 11).

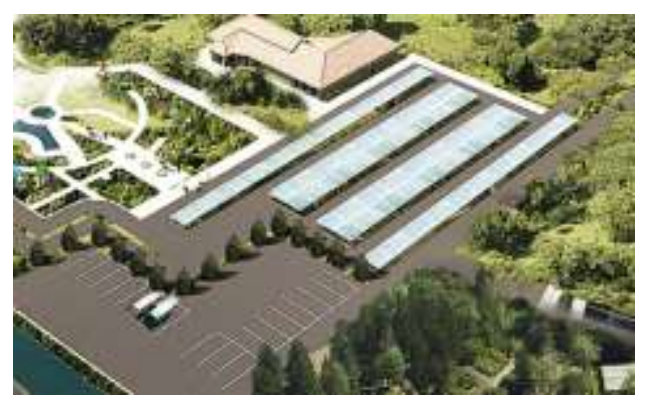

Gambar 11. Panel Surya Sebagai Atap Area Parkir

\section{REFERENSI}

Karyono Tri Harso, 2010, Green Architecture: Pengantar Pemahanan arsitektur Hijau di Indonesia

Brenda dan Vale, 1991, Green Architecture: Design For A Sustainable Future

Christina E.M, 2013, Hemat Energi Dan Lestari Lingkungan Melalui Bangunan 